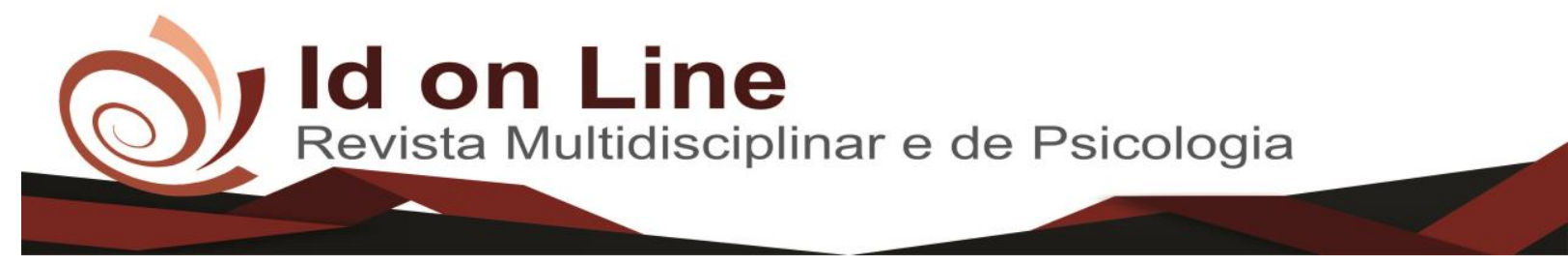

Comment

\title{
O Ensino/Aprendizagem de Crianças Disléxicas nas Séries Iniciais do Ensino Fundamental
}

\author{
Cleonice Clementino de Menezes ${ }^{1}$; Maria do Socorro Alves Januário²; \\ Maria do Socorro Cecílio Sobral ${ }^{3}$
}

\begin{abstract}
Resumo: O presente artigo apresenta-se com uma pesquisa bibliográfica que busca identificar as bases teóricas que sustentam o processo ensino/aprendizagem de crianças com dislexia nas séries iniciais do ensino fundamental. Alicerçada na reflexão de leituras e análises de textos de autores renomados como Jardine (2010), Fonseca (2011), Moura (2012), Ohlweiler (2016), onde discutem com precisão a temática abordada. O objetivo deste estudo é investigar quais são meios eficazes para a efetivação de uma prática pedagógica adequada as crianças disléxicas. Como resultado o estudo mostrou que é preciso encorajá-las, compreendê-las e dispor de muita paciência, pois o aluno disléxico leva muito tempo para aprender. A metodologia utilizada deu-se através de análises de textos dos autores antes citados, dos quais dá embasamento do que é a dislexia, sua apresentação nas formas de linguagem, as dificuldades de leitura, aquisição e capacidade da escrita e compreensão de textos. Conclui-se que há grande necessidade de uma prática pedagógica eficaz no atendimento as crianças disléxicas no âmbito escolar. É preciso repensar essas práticas de modo a desenvolver uma aprendizagem significante e inclusiva.
\end{abstract}

Palavras-chave: Dislexia. Transtornos. Leitura e escrita. Aprendizagem.

\section{The Teaching-Learning of Dyslexic Children in the Early Years of Elementary School}

\begin{abstract}
This article presents a bibliographical research that seeks to identify the theoretical bases that support the teaching / learning process of children with dyslexia in the initial grades of elementary school. Based on the reflection of readings and analysis of texts by renowned authors such as Jardine (2010), Fonseca (2011), Moura (2012), Ohlweiler (2016), where they discuss precisely the subject matter. The aim of this study is to investigate which are effective means for the accomplishment of an adequate pedagogical practice for dyslexic children. For this to happen, it is necessary to encourage them, to understand them and to have a lot of patience, since the dyslexic student takes a lot of time to learn. The methodology used was based on the analysis of the texts of the authors mentioned above, of which it is based on dyslexia, its presentation in the forms of language, difficulties in reading, acquisition and writing ability and comprehension of texts. There is a great need for an effective pedagogical practice in the care of dyslexic children in school. These practices need to be rethought in order to develop meaningful and inclusive learning.
\end{abstract}

Keywords: Dyslexia. Disorders. Reading and writing. Learning.

\section{Introdução}

Este artigo tem como finalidade abordar o processo ensino/aprendizagem de crianças com dislexia nas séries iniciais do ensino fundamental.

\footnotetext{
${ }^{1}$ Faculdade de Ciências Humanas do Sertão Central (FACHUSC). - cleomenezes80@ hotmail.com

${ }^{2}$ Faculdade de Ciências Humanas do Sertão Central (FACHUSC). - socorroalvesjanuario@ hotmail.com

${ }^{3}$ Mestrado em Educação em Ciências pela Fundação de Apoio à Universidade Federal do Rio Grande do Sul, Brasil. Faculdade de Ciências Humanas do Sertão Central (FACHUSC). socorrosobral@ bol.com.br
} 
Tenta descrever conceitos da dislexia sobre a visão de autores, dificuldades específicas da aprendizagem, onde se destaca diferenças entre dificuldade e transtorno da aprendizagem e como ambas interfere na aprendizagem

escolar. Também aborda o transtorno da leitura como causa complementadora de outros saberes.

As dificuldades na escrita e leitura nas crianças são cada vez mais frequentes na escola e muitas vezes são atribuídas a transtornos de aprendizagem. Dependendo dos problemas ocorridos no ato da aprendizagem das crianças, intitula-se de dislexia.

Mesmo dispondo de inteligência, visão e audição normais, lares e convivência adequada, a incapacidade de a criança ler e compreender o que lê, denomina-se por de dislexia. Definida como um transtorno de aprendizagem, é um distúrbio de maior incidência nas salas de aula no mundo todo, muitas vezes confundida de uma má alfabetização, desatenção ou ausência de motivação. Quando não tratada adequadamente, compromete a fase adulta da criança. Porém, rotular uma criança com dificuldade de leitura como disléxica, não é a ação mais viável na erradicação desta dificuldade. Pois muitas vezes tais dificuldades são derivadas de métodos deficientes e pouca motivação para a leitura.

Com o estudo em questão, anseia-se de forma específica: abordar ato de brincar na educação infantil, indicando-o como sendo papel essencial no desenvolvimento biopsicossocial da criança; o lúdico como recurso essencial à aprendizagem, destacando a importância da vivência lúdica das crianças na Educação Infantil e os caminhos a se percorrer; as brincadeiras, de forma específica: abordar o processo ensino/aprendizagem de crianças com dislexia nas séries iniciais do ensino fundamental, compreendendo-o, portanto que o termo dislexia referese a um distúrbio de aprendizagem que atinge o ser humano com dificuldades específicas na área da leitura e escrita; diferenças entre dificuldade e transtorno da aprendizagem, enfatizando pontos de ocorrência e os recursos para saná-los; ressaltando-se, portanto os transtornos da leitura e os seus entraves no processo de aprendizagem.

A dislexia é um distúrbio de aprendizagem que atinge o ser humano deixando-o incapacitado a prática do ler e escrever. Porém o mesmo não acontece com as crianças da mesma faixa etária que possuem inteligência normal, saúde e órgãos sensoriais perfeito, estado emocional considerando normal e instrução adequada.

A escola como espaço de ensino aprendizagem que é, necessita estar preparada para atender as crianças nas suas especificidades, com ações que ofereça condições, 
ferramentas,recursos pedagógicos e formação continuada, possibilitando assim a mediação de aprendizagens significativas.

\section{Referencial Teórico}

\section{Dislexia}

Dislexia é um distúrbio específico da linguagem, de origem constitucional, caracterizado pela dificuldade de aprendizagem da leitura, escrita, soletração, memorização, dentre outras, identificadas em diferentes faixas etárias de idade, que afeta a aquisição literária por um número significativo de crianças e adolescentes em idade escolar (ABD. 1994)

Apesar de submetida à instrução convencional, adequada inteligência, oportunidade sócio-cultural e não possuir distúrbios cognitivos e sensoriais fundamentais, a criança falha na aquisição da linguagem. A dislexia é apresentada em várias formas de dificuldade com as diferentes formas de linguagem, como antes ditas, frequentemente incluídas problemas de leitura e aquisição da e capacidade de escrita e pronúncia.

Não se caracteriza como doença, portanto não podemos falar em cura. Ela é congênita e hereditária, e seus sintomas podem ser identificados logo na pré-escola. Os sintomas podem ainda ser aliviados, contornados, com acompanhamento adequado direcionado às condições de cada caso. Não podemos considerar como "comprometimento" sua origem constitucional (neurologia), mas como uma diferença, que é notada à dominância cerebral.

Para Jardine (apud SILVA, 2010), dislexia é a dificuldade específica em leitura e, como tal, compreende duas vertentes fundamentais: a decodificação e compreensão. Compreende-se por decodificação a capacidade linguística que os escritores, leitores, e estudantes têm em associar um signo gráfico a um nome ou a um som. Já compreensão, por capacidade que o ser humano tem de assimilar e entender algo que lhe está sendo colocado, seja por meio da leitura ou da escrita de um determinado signo gráfico.

Já para Fonseca (apud SILVA, 2011), tanto o critério da ausência de habilidade no nível fonológico, como a dificuldade no reconhecimento de vocábulos é contínuo. Nas suas averiguações o autor exclui os fatores socioeconômicos e o fator de inteligência. Para ele, os 
disléxicos são na verdade, seres muitos talentosos e com habilidades básicas comuns, que se não forem excluídas pela sociedade, resultarão em extraordinária criatividade.

Assim sendo, é necessário saber quais os tipos de dislexia, suas características e os aspectos correlacionados com a aprendizagem.

Conforme Ianhez (2002), a dislexia pode ser classificada em:

a) dislexia visual, também chamada de diseidética ou superficial, caracterizada por dificuldade no processamento visual, na qual a criança lê por meio de processo elaborado de análise e síntese fonética e disfunção no lobo occipital. Porém, não está relacionada com problemas de visão, só com a inabilidade de captar o que se vê. Este tipo de dislexia é o mais fácil de corrigir, por meio de exercícios adequados, podem-se aprender os signos gráficos com precisão e gradualmente aprender sequencias, porém, a lentidão pode persistir;

b) dislexia auditiva, (disfonética ou fonológica), caracterizada por dificuldades na leitura oral de palavras pouco familiares, na conversão grafema-fonema e possível disfunção no lobo temporal. É a impossibilidade em discriminar os sons de letras, reconhecer variações de sons, sequencias de, palavras, ordens e histórias. Esta forma de dislexia é a mais difícil de corrigir e fixa na inabilidade de perceber os sons descontínuos da oralidade;

c) dislexia mista caracteriza-se pela presença dos dois tipos anteriores, sendo associada à disfunção dos lobos pré-frontal, occipital e temporal.

Como explica Moura (apud SILVA,2013) o cérebro dos disléxicos é normal, porém, estes recebem informações em áreas diferentes no cérebro o que resultam falhas nas conexões cerebrais, resultando dificuldades de aprender a ler, escrever, soletrar, pois é difícil assimilarem as palavras.

Desde a Pré-escola os sinais e os sintomas podem oferecer pista que a criança é disléxica. Estes, contudo, são insuficientes para se fechar um diagnóstico, mas vale ter atenção: como o fraco desenvolvimento da atenção, a falta de capacidade para brincar com as outras, o atraso na fala, na escrita, no desenvolvimento visual, na motora, em aprender canções, falta de interesse em livros impressos, dificuldade em acompanhar história e dificuldade com a memória imediata. Copiam de forma errada as palavras, mesmo observando na lousa ou nos livros como são escritas. "Como podem? A criança está vendo a forma correta e escreve exatamente o contrário?” Ora, o processamento da informação léxica, que é de ordem cerebral, está invertida ou simplesmente deficiente. É importante ainda, observar que a pronúncia ou a soletração de palavras monossílabas é um problema evidente nos disléxicos; não se esquecendo do problema 
em distinguir esquerda e direita. Mas o primeiro sinal da dislexia pode ser um atraso na fala. Embora o atraso ao falar possa ser de origem familiar, a dislexia também o é.

Compreende-se, portanto que detectar um distúrbio não é uma tarefa fácil. Pois sinais e sintomas podem até ser dislexia, porém um diagnóstico preciso só é possível a partir do momento que a leitura e a escrita são apresentadas formalmente à criança, a partir dos cinco anos de idade.

\section{Dificuldades específicas da aprendizagem}

Os termos utilizados, tais como "distúrbios", "dificuldades", "problemas", “incapacidades", "transtornos", são encontrados na literatura e, muitas vezes, são empregados de forma inadequada. Na tentativa de permitir uma comunicação mais adequada entre os que atuam na área da aprendizagem, é importante a existência de uma terminologia uniforme.

Dessa forma, é importante fixar diferenças entre dificuldade e transtorno da aprendizagem. Muitas crianças em fase escolar apresentam certas dificuldades em realizar uma tarefa, que podem surgir por problemas na proposta pedagógica, na capacitação do professor, problemas familiares ou déficits cognitivos, entre outros.

Apresentar uma dificuldade de aprendizagem não implica necessariamente um transtorno, uma vez que este se traduz por um conjunto de sinais sintomatológicos provocadores de inúmeras perturbações na aprendizagem da criança, interferindo na aquisição e manutenção de informações acentuadas.

As dificuldades de aprendizagem podem ser causadas por problemas escolar ou familiar que nem sempre oferecem condições adequadas para o sucesso da criança. Nessa categoria, também se incluem as dificuldades que a criança pode apresentar em alguma matéria ou em algum momento da vida, além de problemas psicológicos, como falta de motivação e autoestima. Os problemas de aprendizagem podem ser secundários a outros quadros diagnosticáveis, tais como alterações das funções sensoriais, doenças crônicas, transtornos psiquiátricos, deficiência mental e doenças neurológicas como paralisia cerebral e o transtorno de déficit de atenção/hiperatividade (TDAH), deficiência mental, transtorno do espectro autista e epilepsia. 


\section{Os Transtornos da Aprendizagem}

Os transtornos da aprendizagem compreendem uma inabilidade específica, como de leitura, escrita ou matemática, em indivíduos que apresentam resultados significativamente abaixo do esperado para no desenvolvimento das habilidades escolares intelectuais. O mesmo apresenta-se na criança com as seguintes características:

- Inteligência normal;

- Ausência de alterações motoras ou sensoriais;

- Bom ajuste emocional;

- Nível socioeconômico e cultural aceitável. (ADAMS, 2016, p.108).

Segundo OHLWEILER (2016, p.108), é necessário diferenciar os transtornos das variações normais nas realizações escolares. Os transtornos específicos do desenvolvimento das habilidades escolares compreendem grupos de transtornos manifestados por comprometimentos específicos e significativos no aprendizado de habilidades escolares. Esses comprometimentos no aprendizado não são resultado direto de outros transtornos, ainda que eles possam ocorrer simultaneamente. As dificuldades de aprendizagem podem estar presentes desde os primeiros anos de vida, o que pode ser evidenciado por um atraso na prática das habilidades em questão. Pode-se observar que, apesar do atendimento específico, o problema que a criança apresenta persiste, muitas vezes por toda a vida. Menciona-se, portanto a genética, à qual se atribui, por exemplo, a origem da dislexia.

Para melhor compreensão dos problemas de aprendizagem, listam-se aqui os transtornos específicos da aprendizagem, nos quais tanto CID-102 quanto o DSM-53, se apresentam basicamente em três tipos específicos: o transtorno da leitura, o transtorno da matemática e o transtorno da expressão escrita:

- Transtorno da leitura: é caracterizado por uma dificuldade específica em compreender palavras escritas. Trata de um transtorno específico das habilidades de leitura, em que foram eliminadas todas as outras causas.

- Transtorno da matemática: também conhecido como discalculia, não é relacionado à ausência de habilidades matemáticas básicas, como contagem, e sim à forma com que a criança associa essas habilidades com o mundo que a cerca. A aquisição de conceitos matemáticos, bem como de outras atividades que exigem raciocínio, é afetada nesse transtorno, cuja baixa 
capacidade para manejar números e conceitos matemáticos não é originada por lesão ou outra causa orgânica.

- Transtorno da Expressão escrita: refere-se apenas à ortografia ou caligrafia, na ausência de outras dificuldades da expressão escrita. Nesse transtorno, geralmente há uma deficiência na capacidade de compor textos escritos, evidenciada por erros de gramática e pontuação dentro das frases, má organização dos parágrafos, múltiplos erros ortográficos, na ausência de outros prejuízos na expressão escrita.

O aprendizado é um processo complexo, dinâmico, que resulta em modificações estruturais e funcionais permanentes do SNC (Sistema nervoso central). As modificações ocorrem a partir de um ato motor e perceptivo, que, elaborado no córtex cerebral, dá origem à cognição. Assim podem ser classificadas levando-se em conta as funções afetadas, que são as funções psicológicas superiores. Estas são aprendidas desde o nascimento e são fundamentais para o aprendizado formal. (OHLWEILER, 2016, p.107-109)

Entender as funções psicológicas superiores do ser humano é o caminho mais viável para compreendê-lo como ser que se relaciona com o mundo e que vive,ou espera-se que viva na a coletividade, construindo seu conhecimento através das interações mediada por diversas relações intra e interpessoais.

\section{Transtorno da leitura}

A leitura é uma forma complexa de aprendizagem simbólica, na qual mudanças relativamente triviais em uma palavra podem alterar completamente sua pronúncia e seu significado.

As dificuldades na leitura podem afetar toda a vida escolar da criança. Pois, na progressão dos anos letivos, a aprendizagem de outras disciplinas depende cada vez mais do ler e escrever.

Quando nos alfabetizamos, usamos duas vias para a compreensão leitora e para a produção escrita. Uma delas é a via fonológica e a outra é a via lexical. Pela via fonológica, aprendemos consciência fonológica, reconhecendo os sons de uma determinada língua e suas representações ortográficas. Pela via lexical, aprendemos, por sua vez, a representação da escrita e de grafemas (como sílabas),(CASA CUCA,2011). 
Algumas pessoas, ao se alfabetizarem, têm preferência por uma das vias: a fonológica ou a lexical. Outras pessoas usam as duas vias indistintamente. É importante ressaltar que os dois acessos à alfabetização são dependentes e fortalecem-se de maneira conjunta.

Quando uma criança possui dificuldades de leitura, é possível que na sua alfabetização esses acessos, tenham sido a si ignorado.

Portanto, é necessário compreendermos que a alfabetização não é uma técnica baseada em exercícios motores, mas num complexo fenômeno do qual engloba vários processos cognitivos.

É preciso entender ainda que a alfabetização e o letramento são práticas relacionadas, que precisam ser trabalhadas em práticas de letramento, o que torna o universo escrito e o prazer da criança na leitura pautas relevantes.

Ler é uma das habilidades mais importantes na vida escolar e social do ser humano. Várias das disciplinas na escola dependem da fluência em leitura. A falta de leitura em uma criança impossibilita-o o acesso a outros saberes.

Uma criança com dislexia lê comparativamente mal, podendo, por exemplo, confundir letras simétricas como p e q, b e d, ou começar a escrever com caligrafia ilegível, entre outros comportamentos. Mas podem também desenvolver outras habilidades com resolver simples problemas.

A dislexia envolve geralmente a capacidade de processamento dos sons da fala e da pronuncia das palavras.

A partir das dificuldades de decodificação de níveis menores de linguagem, se origina a falta de compreensão de uma unidade maior como uma frase ou um texto. Estudos apontam que as intervenções mais eficientes para pessoas disléxicas trabalham sobre o exercício de consciência fonológica e de letramento.

Brandão (2015, p.12) ressalta que "a aprendizagem é um processo mental ativo, tendo em vista, aquisições, por meio das quais a lembrança do conteúdo internalizado e o uso deste conhecimento fazem com que o sujeito possa dominá-lo e manipulá-lo, quando necessário".

As crianças com dislexia, normalmente apresentam um quadro onde está presente a dificuldade na aprendizagem, entretanto, em contrapartida, desenvolvem outras habilidades. Dessa forma, é necessário o desenvolvimento de atividades que lhes propiciem liberdade de ação, promovendo um ambiente relacional, oferecendo-lhes condições de superar as 
dificuldades e principalmente conhecendo a importância das brincadeiras no seu desenvolvimento.

Moura (2013) salienta que é de responsabilidade do orientador pedagógico juntamente com a sua equipe, através de estudos, analisar habilidades e interesses dos alunos, bem como as estratégias e os recursos que os atendam nas suas respectivas dificuldades.

Assim sendo, cabe ao orientador pedagógico auxiliar os professores no planejamento nos seus planejamentos, com atividades que propicie liberdade de ações às crianças. Destacase, neste caso, a importância das brincadeiras, como meio eficaz no desenvolvimento do processo das aprendizagens.

As escolas precisam ter consciência do seu papel nas tomadas de iniciativas que demonstrem a construção de metodologias que atendam de fato os alunos com dislexia, auxiliando-os na superação dos obstáculos dos quais impedem sua evolução.

\section{Metodologia}

A metodologia aplicada buscou fornecer os instrumentos necessários a realização de uma pesquisa qualitativa bibliográfica, fazendo uso de leitura e análises de textos, dos autores renomados: Jardine (2010), Fonseca (2011), Moura (2012), Ohlweiler (2016), dos quais forneceu subsídios necessários ao conhecimento da prática do ensino/aprendizagem de crianças disléxicas nas séries iniciais do ensino fundamental. Busca-se com este trabalho auxiliar educadores na compreensão de como lidar com crianças disléxicas na escola, propiciando a eles uma vida feliz sem exclusão nem por parte da escola, nem da família e nem da sociedade.

\section{Resultados e Discussões}

Mediante o estudo realizado foi possível perceber que a dislexia, apresenta-se em vários tipos: auditiva, visual e mista, com diversas formas de dificuldades e com diferentes formas de linguagem, frequentemente incluídas problemas de leitura e aquisição da e capacidade de escrita e pronúncia. 
Nota-se que através dessa investigação que é necessário cada educador saber quais os tipos de dislexia, suas características e os aspectos correlacionados com a aprendizagem do estudante.

Conforme esse estudo foi detectado que as escolas precisam ter consciência do seu papel nas tomadas de iniciativas de construção de metodologias que atendam alunos com dislexia, auxiliando-os na superação dos obstáculos dos que impedem sua evolução.

De acordo com essa investigação percebeu-se que as dificuldades de aprendizagem podem ser causadas por problemas escolar ou familiar que incluem: problemas psicológicos, falta de motivação, autoestima , dificuldade em alguma matéria ou momento, doenças neurológicas como paralisia cerebral, transtorno de déficit de atenção/hiperatividade (TDAH), deficiência mental, transtorno do espectro autista e epilepsia essas e outras dificuldades demoram a serem diagnosticadas, delas apresentam-se confusas e sem preciso diagnostico, nesse sentido corrobora Adams 2016 p.107 quando afirma:

As dificuldades específicas de aprendizagem se referem àquela situação que ocorre com crianças que não conseguem evoluir compatível com sua capacidade cognitiva e não apresentam problemas auditivos, visuais, sensoriais ou psicológicos importantes que possam explicar tais dificuldades.

Nessa pesquisa observou-se que é realmente difícil desenvolver ações de leitura e escrita no ambientes escolar e familiar, sobretudo com estudante disléxico porque nem sempre a família e a escola oferecem condições adequadas para o desempenho e evolução da criança .

\section{Considerações Finais}

Neste trabalho foi discorrido um tema de primordial importância para o ensino/aprendizagem de crianças disléxicas nas séries iniciais do ensino fundamental. Marcado pelo objetivo central de analisar a dislexia e os seus diversos tipos, bem como os transtornos causadores de deficiências na aprendizagem.

Certa de que a dislexia é tida como um distúrbio provocador de dificuldades no processo da leitura e da escrita, que é a produzida pelas bases neurológicas e fatores genéticos ou adquiridos, não deve ser caracterizada como doença, mas por um distúrbio que pode ser 
corrigido se cedo for diagnosticado, pois mesmo que uma pessoa venha apresentar este distúrbio, ela pode dispor de um grau de inteligência normal.

A leitura não pode ser vista unicamente limitada à transmissão de conteúdos, mas também visa formar o hábito como aquisição de conhecimentos constantes para a vida. Com base nas informações adquiridas sobre os danos causados no ensino aprendizagem das crianças com dislexia, o professor, o coordenador e a família precisam junto buscar soluções que amenizem o problema uma vez que têm a mesma responsabilidade social com estes seres. É necessário compreender que ser portador deste distúrbio não significa necessariamente estar impossibilitado ao ato de aprender.

Para a efetivação do aprender acontecer nas instituições escolares é indispensável à prática da afetividade, da dedicação, do cuidado, pois as práticas educativas precisam ser atos positivos, com total apoio, respeito e aceitação das crianças como elas são sem nenhuma forma de exclusão.

Por fim faz-se necessário propiciar ao disléxico uma educação de qualidade e para que isso aconteça é preciso encorajá-lo, compreendê-lo e dispor de muita paciência, pois a aprendizagem para este é mais lenta e requer maior atenção.

Espera-se com este trabalho auxiliar educadores e pais a lidar com os disléxicos, propiciando a eles uma vida feliz sem exclusão nem por parte da escola e nem na vida familiar.

\section{Referências}

Associação Brasileira de Dislexia (ABD). Disponível em: 〈http://www.dislexia.org.br>. Acesso em: 09 set. 2018.

BRANDÃO, Letícia Peixoto Morais. Dislexia: Características e Intervenções.Especialização em Educação Especial e Inclusiva. Universidade Cândido Mendes. Rio de Janeiro: RJ. 2015.

FONSECA, Rosamaria Maria Reboredo Martins da. O desenvolvimento da competência linguística na Dislexia. Especialização em Psicopedagogia Institucional. Universidade Cândido Mendes. Rio de Janeiro: RJ. 2011.9

IANHEZ, Maria Eugênia e NICO, Maria Ângela. Nem sempre é o que parece: como enfrentar a dislexia e os fracassos escolares. São Paulo: Elsevier, 2002

JARDINI, Renata. Dislexia. São Paulo Disponível em: < http:// www.oqueedislexia>. Acesso em: 11 set. 2018. 
MOURA, Suzana Paula Pedreira Tavares de. A dislexia e os desafios pedagógicos. Especialização em Orientação Educacional e Pedagógica. Universidade Cândido Mendes. Niterói: RJ. 2013.

NORMAN, Doidge, O cérebro que se transforma. Como a neurociência pode curar as pessoas. Casa cuca. Instituição de ensino. Ed. Record. 2011.

OHLWEILER, L.; RIESGO, R. dos S. (Orgs.). Transtornos da aprendizagem: abordagem neurobiológica e multidisciplinar. Porto Alegre: Artmed. 2016.

\section{Como citar este artigo (Formato ABNT):}

MENEZES, Cleonice Clementino de; JANUÁRIO, Maria do Socorro Alves; SOBRAL, Maria do Socorro Cecílio. O Ensino/Aprendizagem de Crianças Disléxicas nas Séries Iniciais do Ensino Fundamental. Id on Line Rev.Mult. Psic., 2018, vol.12, n.42, Supl. 1, p. 536-547. ISSN: 1981-1179.

Recebido: 08/11/2018;

Aceito: 12/11/2018 